\title{
Strategic Path for the Development of Live Pig Healthy Breeding Industry in China
}

\author{
Qing Liu ${ }^{1}$, Fengjun $\mathrm{Lu}^{1}$, Gangyi Wang ${ }^{2}$, Wenhai Wang ${ }^{1}$, Xiaohong $\mathrm{Li}^{1}$, Liming Chen ${ }^{1}$ and Xiaofeng Liu ${ }^{3}$ \\ 1. College of Economics and Management, China Agricultural University, Beijing 100083, China \\ 2. College of Economics and Management, Northeast Agricultural University, Harbin 150030, China \\ 3. The Chinese Academy of Social Sciences, Beijing 100836, China
}

\begin{abstract}
The objective of study in the paper was to analyze advantages, disadvantages, opportunities and threats of development of pig healthy agriculture in China, using systematic analysis and SWOT strategic analysis, as well as to show severe diseases, abnormal fluctuation, misplaced way and versatile environment confronted by pig breeding in China. The paper establishes "double-hug mode", from which pig breeding industry transforms and upgrades to modern breeding industry. Combing with the designed multi-party cooperation mechanism of advantageous regions, urban sale areas and group corporations, it sets up three paths for development of pig healthy agriculture in China, i.e., strategic paths of advantageous regions, urban sale areas and group corporations oriented, with an attempt to provide strategic path reference for transformation and upgrading of pig breeding in China and mode reference for breakthrough of development strategy for pig healthy industry.
\end{abstract}

Key words: Pig healthy industry, strategic system, path mode, advantageous regions oriented path, urban sale areas oriented path, group corporation oriented path.

\section{Introduction}

\subsection{Background}

China is at the historical stage, traditional agriculture is transforming to modern agriculture, land, water and labor resources are insufficient and new urbanization is being pushed rapidly, which all bring severe challenge to development of live pig healthy agriculture. To develop healthy breeding is basic path for development of Chinese live pig breeding. Live pig healthy breeding is a kind of breeding mode with high economic, social and ecological comprehensive efficiency, and development of live pig healthy breeding is a systematic, dynamic and integrated process that realizes innovation relying on strategy, guides by objective standard system, supports with organization system establishment and operates by guarantee system. China's live pig breeding is confronted with many issues, such as severe diseases,

Corresponding author: Fengjun Lu, professor, research field: management of agriculture industry chain. abnormal fluctuation, misplaced way and versatile environment, therefore, how to establish strategic system of development for live pig healthy breeding to guarantee consumption, breeding, environment and occupation health and investment and operation of industry chain is critical.

\subsection{References}

Pan and Kinsey [1] systematically analyze every link during Sino-US pork production chain procedure and work out that there are scattered farmers, imperfect information and logistics during Chinese live pig industry chain, resulting in low efficiency in operation of live pig industry chain. Williamson [2] delivers that high quality and safe price to terminal of pork industry chain by making use of connected effect of price system for pork industry is good to realize object, which improves overall economic benefits of pork industry chain. Klepper and Simons [3] believes that system innovation is precondition to guarantee mode optimization of live pig industry chain, smooth 
transaction and reduce transition cost. Holt and Johnson [4] put forward that we must do well in integration and overall system optimization of live pig industry chain in order to push live pig industry chain to walk towards road with orderly competition, virtuous circle and sustainable and healthy development. Azzam et al. [5] develop a comparative statics model of long-run industry equilibrium in the presence of size-based environmental regulation stringency and applies the model to the US hog industry. Moyer et al. [6] concern about potential, uncertain environmental impacts and an outdated regulatory framework leading to a moratorium on new hog industry operations and a provincial hearing. Meulenberg and Pennings [7] propose a marketing strategic approach to commodity futures exchanges to optimize the (hedging) services offered.

\subsection{Significance}

The research object of this paper is the strategic path of the development of the pig breeding industry in China. Through the systematic analysis of the environmental conditions of the development of pig breeding industry, the paper points out that China's pig breeding industry is faced with the deep level of the problem, and tries to explore the transition from traditional culture to modern healthy breeding of Chinese pig breeding. It will provide ideas for different types of regional and subject to grasp opportunities and meet challenges, provide the basis for the Chinese government to develop the guiding policy of the pig industry, and provide reference for the research on the path of pig breeding in this field.

\section{Analysis of Environmental Conditions}

\subsection{Development Trend of Live Pig Breeding Industry} at Oversea

By comparison development status with trend of live pig breeding industry at oversea, it can be concluded that there is internationalization, intellectualization and welfare trend in live pig breeding industry:

(1) Internationalization: the multi-national live pig slaughtering and processing enterprises begin to do business all over the world and consequently develop live pig breeding bases, slaughtering and processing industry and market circulation. Live pig trading among countries is becoming closer and closer day by day (Tables 1 and 2);

(2) Intellectualization: in the world, monomer live pig breeding scale is expanding continuously, numbers of farms are decreasing year by year (Fig. 1), industrialization level is increasing constantly, so modernization, informationization and intellectualization degree of live pig breeding are improving;

(3) Welfare: the world are paying more and more attention to animal welfare, and new technologies, such as swine breeding system, hybrid vigor use, artificial insemination, all-in-all-out breeding, early isolation and ablactation of piglet and ideal protein theory, are being promoted and applied rapidly. The animal welfare has become an inseparable and important part of food safety sector. In 1974, EU was the first to

Table 1 Importing quantity of live pig in main countries in 2007-2012 ( $\times 10^{4}$ pigs).

\begin{tabular}{lllllll}
\hline Country & 2007 & 2008 & 2009 & 2010 & 2011 & 2012 \\
\hline USA & $1,000.4$ & 934.8 & 656.5 & 574.9 & 571.6 & 572.5 \\
Russia & 37.7 & 77.0 & 120.2 & 72.8 & 80.0 & 81.0 \\
Mexico & 13.6 & 8.0 & 0.7 & 0.9 & 1.3 & 1.5 \\
China & 0.3 & 1.2 & 0.6 & 0.6 & 1.0 & 1.2 \\
Canada & 0.2 & 0.2 & 0.3 & 0.3 & 0.3 & 0.2 \\
EU & 0.2 & 0.2 & 0.3 & 0.2 & 0.1 & 0.1 \\
\hline Global & $1,054.2$ & $1,030.5$ & 766.8 & 659.2 & 662.1 & 663.3 \\
\hline
\end{tabular}

Table 2 Exporting quantity of live pig in main countries in 2007-2012 ( $\times 10^{4}$ pigs).

\begin{tabular}{lllllll}
\hline Country & 2007 & 2008 & 2009 & 2010 & 2011 & 2012 \\
\hline Canada & $1,003.2$ & 935.7 & 637.6 & 576.1 & 573.0 & 574.0 \\
EU & 90.1 & 150.8 & 221.0 & 161.4 & 165.0 & 170.0 \\
China & 0.1 & 0 & 0.1 & 163.6 & 156.0 & 160.0 \\
USA & 13.7 & 9.7 & 2.1 & 1.5 & 1.3 & 1.4 \\
Russia & 0.1 & 0 & 0.1 & 0.1 & 0.1 & 0.1 \\
\hline Global & $1,268.3$ & $1,260.8$ & $1,021.1$ & 902.8 & 896.4 & 906.5 \\
\hline
\end{tabular}




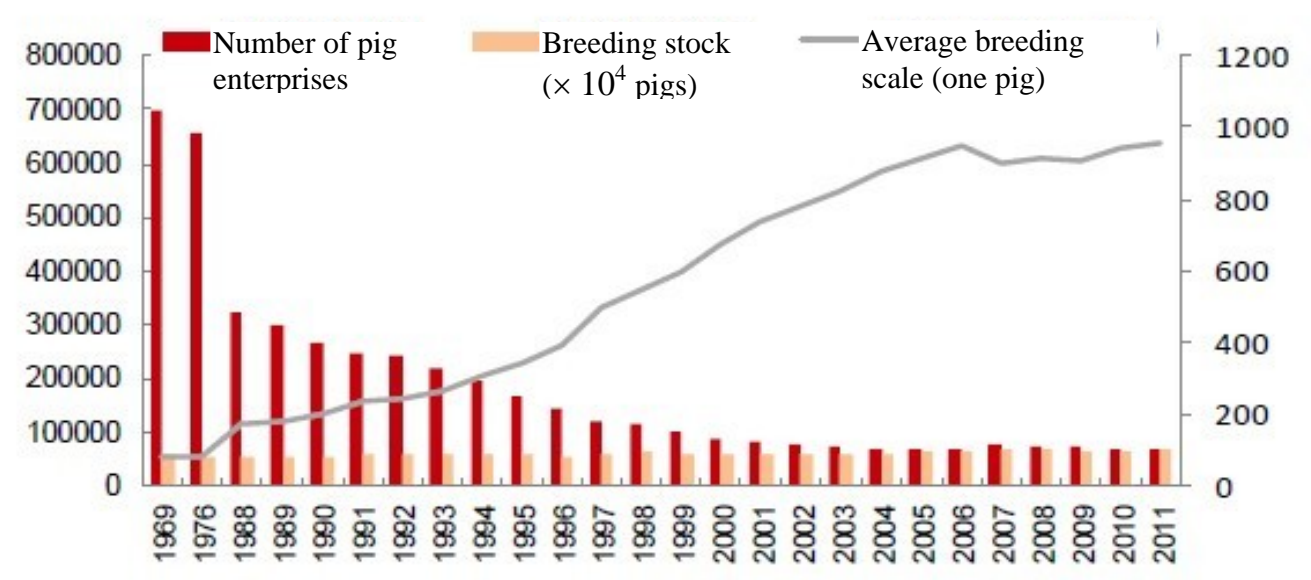

Fig. 1 Statistic of scale level of live pig breeding farm in USA.

establish laws on animal welfare during slaughtering. In January 2006, EU approved specific action plan of animal protection and welfare system perfection, which improved EU animal welfare standard further, integrated relevant animal welfare standards and formed a complete system to be implemented by every country member. From 2007 to 2012, number of animal covered by UK animal welfare system had increased by $50.2 \%$, and cage culture of poultry had been completely eliminated.

\subsection{SWOT Analysis of Live Pig Breeding Industry in China}

2.2.1 Great and Obvious Influence of the Live Pig Breeding Development in China

Based on analysis of data on the development of pig breeding industry, China is a large country that produces, consumes and exports live pig. At the end of 2012, number of breeding stock was 0.473 billion, among which number of reproductive sows was 49,280,000; numbers of pig to be slaughtered was 0.661 billion, pork output was 50,530,000 tons, accounting for $64.76 \%$ of total output of meat and for about $50 \%$ of total output and consumption quantity of pork in the word; percent of live pig breeding industry occupied total output value of animal husbandry was up to $47 \%$. Live pig exporting in China plays critically important role in world trading balance.

\subsubsection{Five Strategic Issues}

The development and expansion of live pig breeding has great influence to increase in farmers' income, food safety, price stabilization and transformation and upgrading, but it is also exposed to development bottlenecks during transformation and upgrading. There are five strategic issues—serious epidemic, abnormal fluctuation, dislocation mode, weak system and environmental risk. It is analyzed through oversea trend that live pig healthy breeding is essential trend for transformation and upgrading of live pig breeding industry. To be specific, based on analysis of data on the development of pig breeding industry and SWOT strategy analysis, the development of live pig healthy breeding in China is faced with the following strength, weakness, opportunity and threat, which are shown in Table 3.

\subsection{Establishment of Value SWOT Mode of} Development for Live Pig Healthy Breeding in China

Based on healthy life, ecological greening and platform innovation, with reform philosophy and thought, development mode transformation, subject relation optimization as grip, we shall break through challenge and restriction of healthy development of live pig industry chain in China, following trend and fashion of healthy development of live pig industry in the world (Fig. 2). 
Table 3 SWOT analysis of development for live pig breeding in China.

\begin{tabular}{|c|}
\hline Strength (S) \\
\hline $\begin{array}{l}\text { (1) Scale strength: China is a large country producing } \\
\text { and consuming live pig with long history breeding } \\
\text { tradition and sound industry foundation. The overall } \\
\text { breeding scale has ranked the first few places in the } \\
\text { world. }\end{array}$ \\
\hline
\end{tabular}

Factors of (2) Capital strength: non-agricultural industry enters internal into breeding industry, which provides capital conditions condition for developing live pig healthy breeding industry and cultivating new type breeding mode.

(3) Reorganization strength: live pig breeding is at the volatile transformation stage, leader, follower and displaced persons are participated in competition at different degrees, and the former reorganizes and pushes industrial resource integration to the latter.

Opportunity (O)

(1) Transformation opportunity: after the 18th Communist Party of China National Congress, China entered into reform and development stage of "five-in-one" and "four modernizations and synchronization", live pig breeding is confronted with the opportunity to production mode transformation Factors of and industry level grading.

external (2) Policy opportunity: central and local government environment pay attention to development of live pig healthy breeding and issue supportive policies related with breeding, production and processing in succession.

(3) Market opportunity: the household consumption demands are changing rapidly, and consumption of quality and quantity for live pig and pork production is increasing day by day.
Weakness (W)

(1) Low matching degree of technology integration: it is difficult for integrating breeding, anti-epidemic, piggery environment and environmental protection techniques, which are necessary for live pig breeding to coordinate and match.

(2) Insufficient service system support: the input support, anti-epidemic, equipment support, science and technology, sale service systems, such as variety, feed, vaccine and veterinary drug necessary during development of live pig healthy breeding are incomplete.

(3) Unit breeding scale is very small: according to statistics from Ministry of Agriculture, at present, number of scale pig farms with more than 500 pigs in China has occupied $38.5 \%$ of total number of pig farms, however, 60,000,000 individual farmers are still main force, and percent of small-scale scattered breeding is still very high.

Threat (T)

(1) Threat of serious epidemic: oneness and inadaptability of species, mismatching of anti-epidemic technology and incomplete social service system are important reasons for frequent epidemic occurrence.

(2) Interruption of abnormal fluctuation: frequent epidemic occurrence, policy control and market influence result in fluctuation of live pig market price, and live pig breeding profit show large fluctuation.

(3) Big risk in environmental change: there are dramatic changes among ecological, epidemic, market, policy and industry environment; water resource is shortage, labor cost increases and land space is limited, which are bad to sustainable and healthy development of live pig breeding.

\subsubsection{Use Strength}

The strengths of large agricultural and industrialized leading enterprises in the aspect of corporate culture and full industry chain brand, multi innovation and fund allocation, industry chain vertical integration mode and comprehensive innovation platform are fully made use to intensify and improve core competition of healthy breeding of live pig in China.

\subsubsection{Internalization Opportunity}

We shall grasp the opportunity to support ruminants, such as dairy cow, beef and mutton sheep from the state, break through the species and input research and the development bottleneck of healthy breeding of live pig, meet the demands for high protein healthy and nutritious food from nationals, as well as create vertical and integrated industry chain mode of healthy breeding of live pig.

\subsubsection{Deal with Opportunity}

We shall explore replacement mode of traditional live pig healthy breeding and search for production way of green and ecological healthy breeding so as to deal with challenges which are brought by high cost, land, labor and water resource and feed raw materials.

\subsubsection{Overcome Weakness}

During operation of live pig breeding industry chain, we shall overcome weakness of low mismatching of technology integration, insufficient service system support and small scale in unit breeding to reduce objective risk caused by epidemic and abnormal fluctuation of live pig healthy breeding in China. 


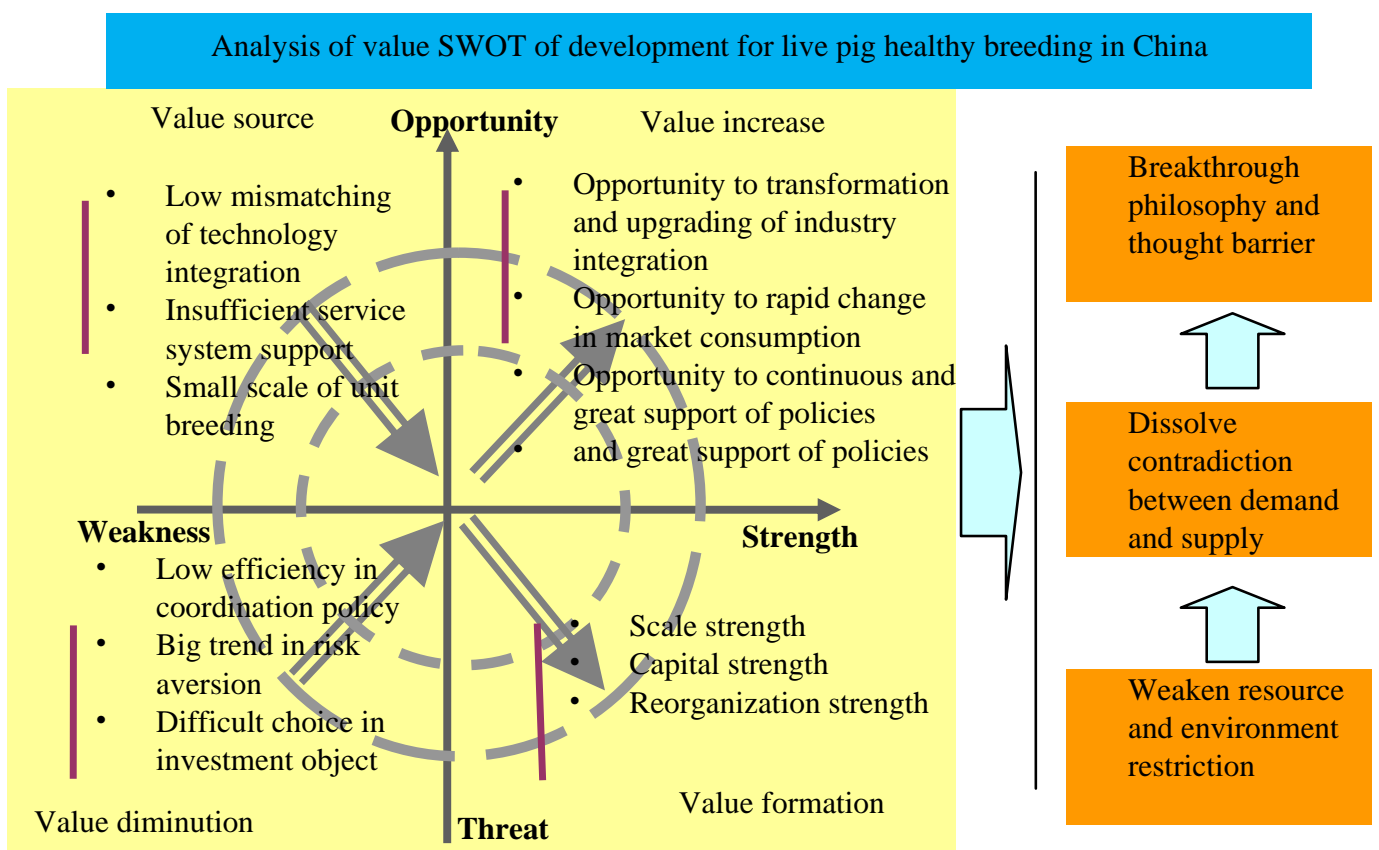

Fig. 2 Value SWOT mode of development for live pig healthy breeding in China.

\section{Strategic Thought}

It is necessary for healthy transformation, upgrading and optimization of live pig industry chain to intensify natual, symbiosis and implantation energy, improve breeding development level and promote structure evolution of live pig industry chain. We shall establish value/energy/level formation and enlargement mode that guides live pig healthy breeding from two dimensions of development level and evolution stage to provide system mode and reorganization foundation for resource, formation, transformation, enlargement, recycling and spinal upgrading for value/energy/level for live pig healthy breeding as well as to provide power source for formation and influence of thought and conscienceness, logistic and fund, energy and value flows for live pig breeding. In Fig. 3, there are three spinal modes [8], which are also called "double-hug mode”. Three spinal modes include value, energy and evolution spinals.

\subsection{Value Spiral}

Value spiral is also called as "double-hug model” of live pig breeding transformation, upgrading and optimization. There is potential difference between live pig healthy breeding and traditional live pig breeding, and work is done through potential energy to affect transformation of live pig industry chain. Interaction between live pig healthy breeding and tranditional live pig breeding will produce game competition symbosis through field energy to affect upgrading of live pig industry chain. Live pig healthy breeding is ultimate development diretion to form new energy and produce spinal and hierarchical cycle energy under influence of subject, mechanism and platform to affect optimization of live pig healthy breeding value chain. Value dynamic evolution of live pig healthy breeding development is affected by energy during the process.

\subsection{Energy Spiral}

Energy spinal refers to iterative spiral among narual, implantation and symbiosis energies. Power source of live pig healthy breeding development mainly replies on narual, implantation and symbiosis energies and shows potential, field and power energy. Natural energy mainly means energy accumulated, inherited 


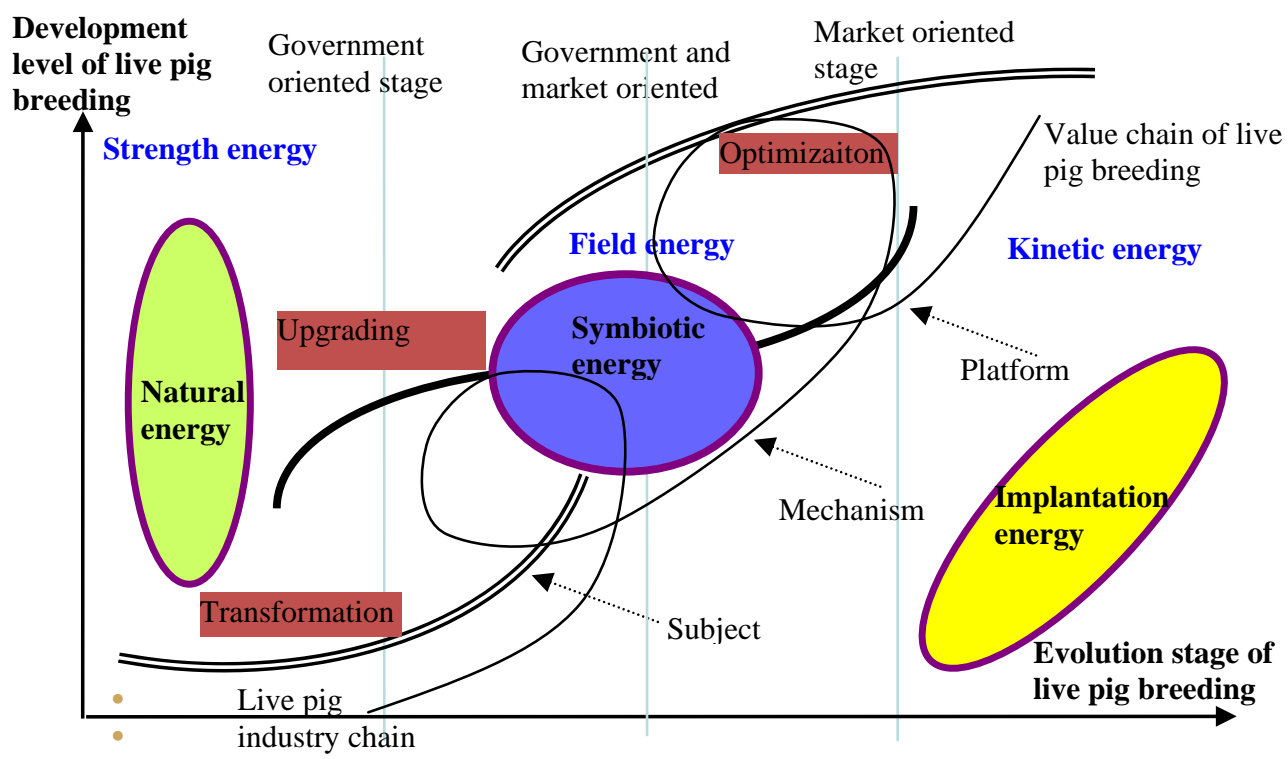

Fig. 3 Three spiral modes of value and energy flow influence of development for live pig healthy breeding.

and left by traditional live pig breeding, symbiosis energery means energy cycle from competition and cooperation symbiosis among relevant subjects of live pig breeding industry chain, and implantation energy means energy injected through external innovation platform or negentropy. Natural energy accumulates to some degree to form potetial energy, symbiosis energery interacts to some degree to form field energy, and implantation energy is impacted externally to some degree to form power energy. Potential, field and power engeries take effect to live pig healthy breeding industry chain together to push transformation, upgrading and optimization of live pig breeding both internally and externally, which promotes the accelerated differentiation and survival of the fittest of subject organization for live pig breeding.

\subsection{Evolution Spiral}

Evolution spinal refers to evolution of development level for live pig healthy breeding from lower, medium to senior level. It mainly means the spiral line on the right, under the influnce from government, consumption, processing and operation and service subjects. The development of live pig healthy breeding will go through evolution from government-oritented stage to both government and market oritented stage and then to market oriented stage, and show trend of evolution from lower, medium to senior level, as thought and conscieous streams, material and fund streams and energy and value streams exchange constantly.

\section{Strategic Path}

The path mode of Chinese live pig healthy breeding refers to set of subjects, such as enterprises, cooperatives, farmers, associates and joints, under influence from both market and government, and are composed of development strategy, action path and mode of breeding market system, complete government function and market and government linkage in order to promote establishment and operation of large breeding bases and industry chain joint organization. To realize five healthy targets of live pig healthy breeding, push the establishment and operation of live pig breeding industry chain organizations, and perfect the profit drive and the promotion, expansion and co-augmentation of mechanisms of live pig breeding, depending on orientation subject, target standard, organization type 
and mechanism guarantee differences of live pig healthy breeding, the path mode of live pig healthy breeding development can be divided into development path modes of advantageous regions, urban sale areas and group corporations oriented.

The study mechanism framework of strategic path for live pig healthy breeding development is a system analysis framework, which is composed of three dimensions of advantageous regions, urban sale areas and group corporations oriented [9]. Each mechanism corresponds and correlates with target, organization and mechanism systems, providing framework foundation for system design of strategic path for live pig healthy breeding development (Fig. 4).

\subsection{Strategic Path of Advantageous Regions Oriented}

It is necessary for live pig healthy breeding development to form and optimize path mode of live pig healthy breeding of advantageous regions oriented.

\subsubsection{Basic Composition}

With advantageous region oriented, it is path mode that perfects and promotes market and government function systems of live pig healthy breeding; with advantageous region oriented, it is path mode that breeds and establishes live pig healthy breeding bases and industry chain (supply chain) alliance; with advantageous region oriented, it is path mode that breeds and establishes market and government function systems, live pig healthy breeding industry bases and industry chain (supply chain) alliance joint mechanism, which is shown in Fig. 5.

\subsubsection{The Formation and Influence}

The formation and influence of path mode for live pig breeding development of advantageous regions oriented is consequently cumulative. Depending on rich resource, advantageous regions and traditional industry, it forms live pig healthy industry of advantageous regions oriented and undertakes advanced breeding mode, technologies, philosophies and systems of market oriented, which provides very sufficient and stable market supply, and effective production base and sale breeding mode for live pig healthy breeding development.

\subsubsection{The Influence}

The formation and optimization of path mode of live pig healthy breeding development of advantageous regions oriented has great influence. The complete government system is external factor for formation and optimization of path mode for live pig healthy breeding of advantageous regions oriented, while live pig healthy breeding industry base with scale, intensification and organization is internal factor for formation and optimization of path mode for live pig healthy breeding of advantageous regions oriented.

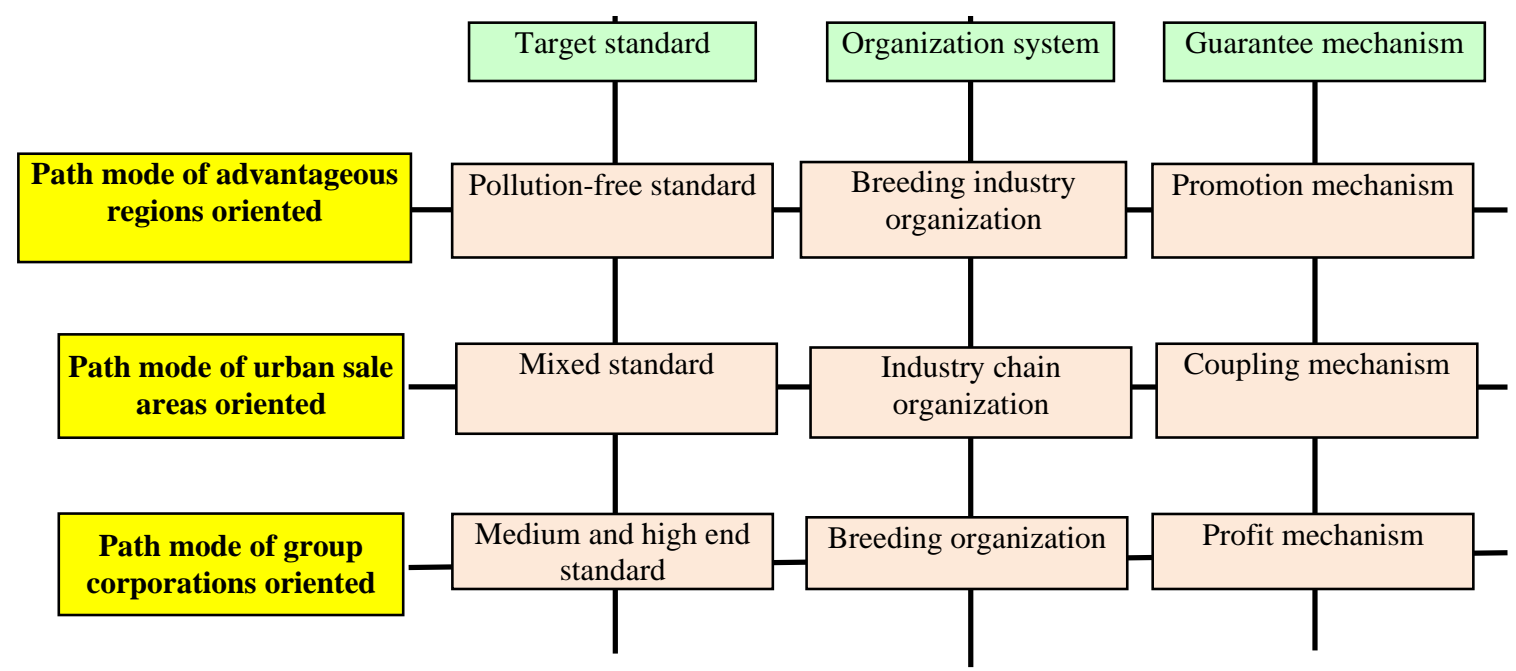

Fig. 4 Mechanism framework of strategic path for live pig healthy breeding development. 


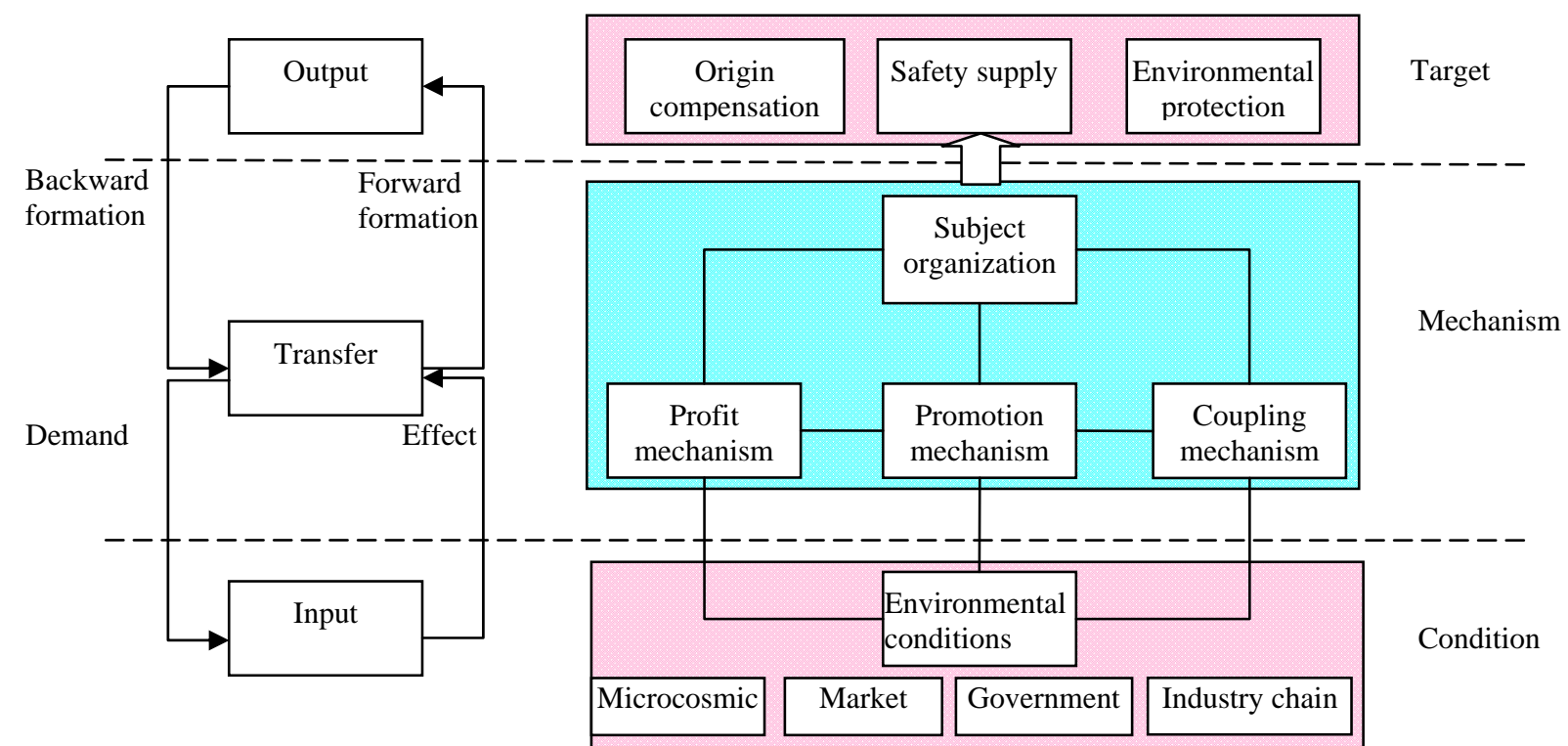

Fig. 5 Study framework of strategic path of live pig healthy breeding development of advantageous region oriented.

\subsubsection{Complementary Relationship}

With advantageous region oriented, to perfect and promote market and government function systems of live pig healthy breeding is external environment; with advantageous region oriented, to breed and establish path mode of live pig breeding healthy breeding bases and industry chain (supply chain) alliances is internal support; with advantageous region oriented, to breed and establish path mode of market and government function systems, live pig healthy breeding industry chain bases and industry chain (supply chain) alliance joint mechanism is development trend.

\subsection{Strategic Path of Urban Sale Region Oriented}

It is necessary for live pig healthy breeding development to form and optimize path mode of live pig healthy breeding of urban sale regions oriented.

\subsubsection{Basic Composition}

With urban sale region oriented, it is path mode that perfects and promotes market function and government function systems of live pig healthy breeding; with urban sale region oriented, it is path mode that breeds and establishes live pig healthy breeding bases and industry chain (supply chain) alliance; with urban sale region oriented, it is path mode that breeds and establishes market and government function systems, live pig healthy breeding industry bases and industry chain (supply chain) alliance joint mechanism, which is shown in Fig. 6.

\subsubsection{The Formation and Influence}

The formation and influence of path mode for live pig breeding development of city urban regions oriented is backward introductory. Depending on rich support and guarantee systems (tax preference, bank and government cooperation, financial support) of consumption market and government in large cities, with support for large enterprise and bases in urban sale regions to establish live pig healthy breeding bases as main form, it provides support in order to satisfy safety consumption demands for live pig and pork, and provides guarantee conditions in order to implement "vegetable basket project" and food safety action plans in urban sale regions, as well as provides mode model for sound interaction relationship among "quality-quantity-price" in large sale regions.

\subsubsection{The Formation and Optimization}

The perfect and complete market function system is external factor for formation and optimization of path mode of live pig healthy breeding development of urban sale oriented; the reasonable profit increase, the 


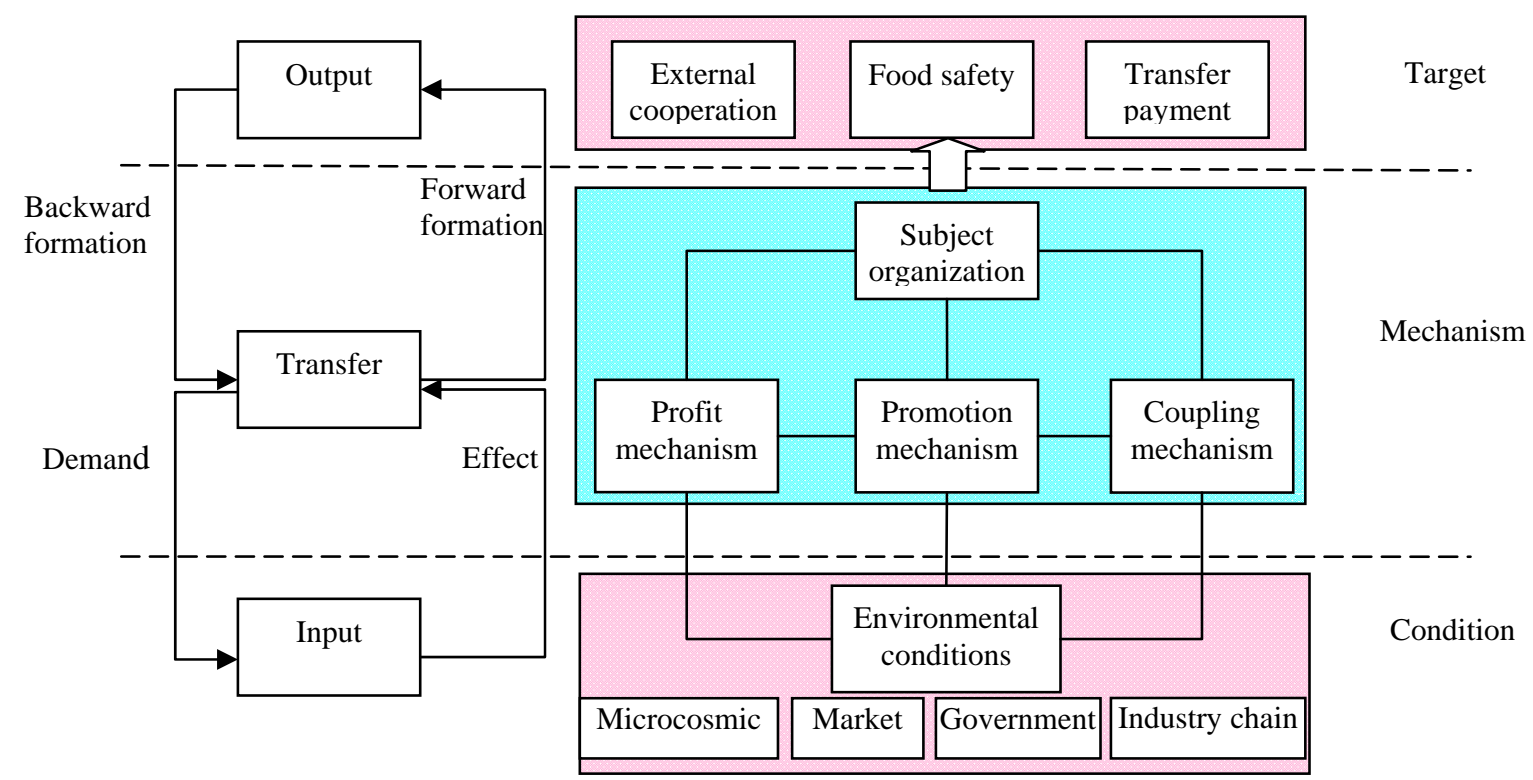

Fig. 6 Study framework of strategic path of live pig healthy breeding development of urban sale region oriented.

adjustment and allocation mechanisms among origin and urban regions, as well as the suitable promotion and cooperation mechanism are internal factor for formation and optimization of path mode of live pig healthy breeding development of urban sale oriented.

\subsubsection{Complementary Relationship}

With urban sale region oriented, to perfect and promote market and government function systems of live pig healthy breeding is basic power; with cooperation between origin and urban regions oriented, to breed and establish path mode of live pig breeding healthy breeding bases and industry chain (supply chain) alliances is replacement measure; with origin and urban regions oriented, to breed and establish path mode of market and government function systems, live pig healthy breeding industry chain bases and industry chain (supply chain) alliance joint mechanism is development guarantee.

\subsection{Strategic Path of Group Corporations Oriented}

It is necessary for live pig healthy breeding development to form and optimize path mode of live pig healthy breeding of group corporations oriented.

\subsubsection{Basic Composition}

With group corporations oriented, it is path mode that perfects and promotes market function and government function systems of live pig healthy breeding; with group corporations oriented, it is path mode that breeds and establishes live pig healthy breeding bases and industry chain (supply chain) alliance; with group corporations oriented, it is path mode that breeds and establishes market and government function systems, live pig healthy breeding industry bases and industry chain (supply chain) alliance joint mechanism, which is shown in Fig. 7.

\subsubsection{The Formation and Influence}

The formation and influence of path mode of live pig breeding development of group corporations oriented is interactive. Depending on close and interactive full industry chain (supply chain), alliance of live pig healthy breeding industry chain (supply chain) and live pig healthy breeding service management company, with increasing enterprises' market operation ability as purpose, by way of standard improvement, customer segment and channel establishment, it has influence to drive and lead full industry to path mode of live pig healthy breeding development.

\subsubsection{The Formation and Influence}

The formation and influence of path mode of live pig breeding development of group corporations oriented 


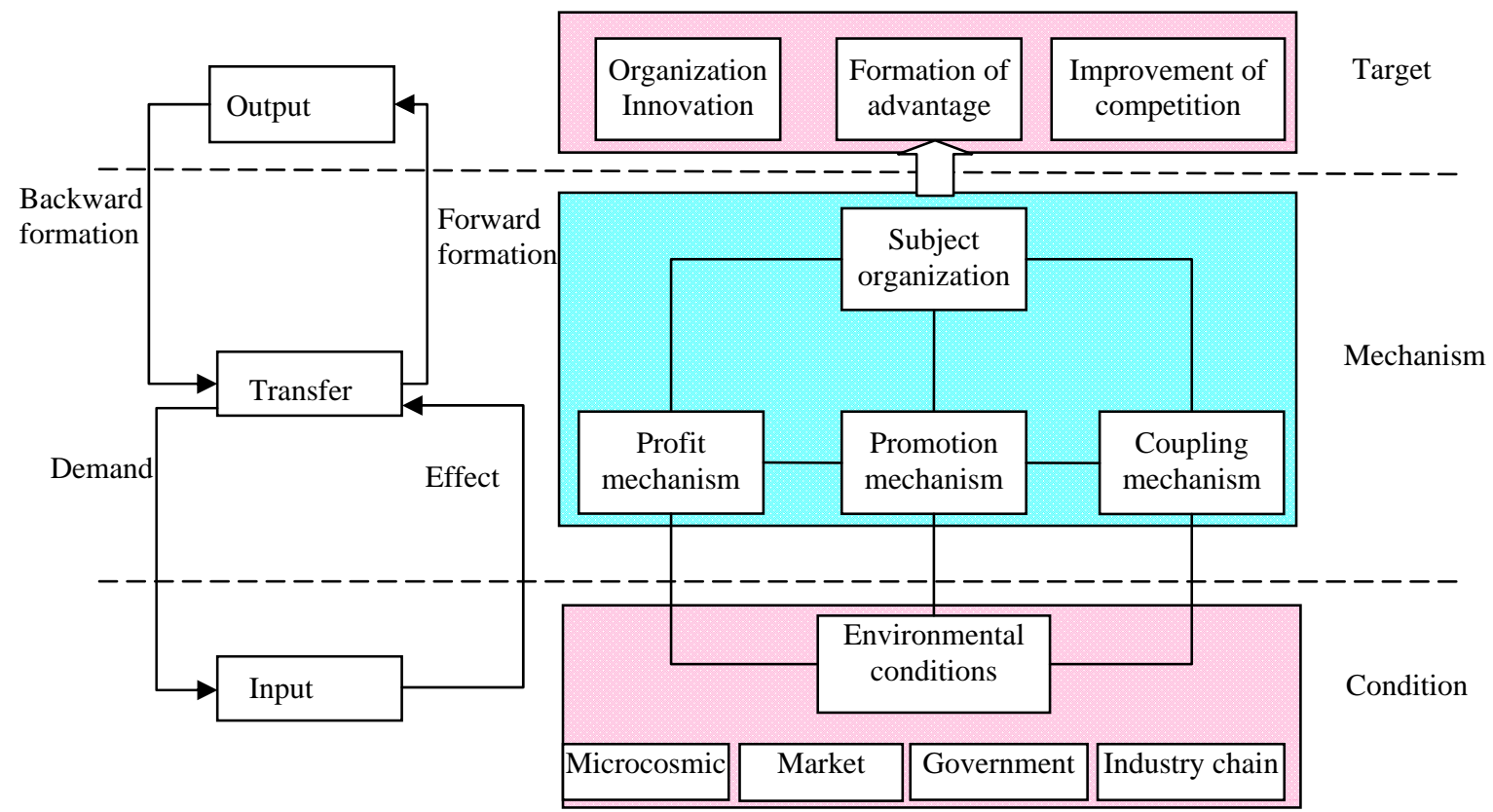

Fig. 7 Study framework of strategic path of live pig healthy breeding development of group corporations oriented.

is affected greatly by target standard system. The target standard system, market function (brand) system and "quaternity" joint mechanism of live pig healthy breeding is external factor for formation and optimization of live pig breeding development of group corporations oriented; internal pursuit of corporation development and leadership-system-culture is internal factor for formation and optimization of live pig breeding development of group corporations oriented.

\subsubsection{Complementary Relationship}

With group corporations oriented, to perfect and promote path mode of market and government systems of live pig breeding development is basic condition; with group corporations oriented, to breed and establish path mode of live pig healthy breeding industry base and chain (supply chain) alliance is support guarantee; with group corporations oriented, to breed and establish path mode of market and government function systems and live pig healthy breeding bases and industry chain (supply chain) alliance joint mechanism is ultimate purpose.

\section{Conclusions}

To develop healthy breeding is basic path for development of Chinese live pig breeding. Live pig breeding in China is confronted with many issues, such as severe diseases, abnormal fluctuation, misplaced way and versatile environment. The development of live pig healthy breeding is a systematic, dynamic and amalgamation process that realizes innovation relying on strategic breakthrough, guides by objective standard system, supports with organization system establishment and operates by guarantee system, while transformation and upgrading of Chinese live pig breeding need to explore various development paths and modes of live pig healthy breeding of advantageous regions, urban sale areas and group corporations oriented. It is worthy to note that path mode of live pig healthy breeding development is affected by demand environment, target condition and subject organization. The comprehensive influence among these environmental conditions will have influence to change in subject action of live pig breeding industry chain.

\section{Acknowledgments}

The authors thank for the support by National Natural Science Foundation of China "The Study of Benefits Safeguards of Healthy Pig Breeding Industry 
and Exemplified Promotion Mechanism” (70873125) and by the collaborative project of Scientific Research and Graduate Training of Beijing Municipal Education Commission (Grant 201502911110426).

\section{References}

[1] Pan, C. J., and Kinsey, J. 2002. "The Supply Management of Pork: US and China.” Working Paper, University of Minnesota. Accessed December 5, 2014. http://ageconsearch.umn.edu/bitstream/14300/1/tr02-01.pdf.

[2] Williamson, O. E. 1971. "The Vertical Integration of Production: Market Failure Considerations.” American Economic Review 61 (2): 112-23.

[3] Klepper, S., and Simons, K. L. 2005. "Industry Shakeouts and Technological Change.” International Journal of Industrial Organization 23 (1-2): 23-43.

[4] Holt, M. T., and Johnson, S. R. 1988. "Supply Dynamics in the US Hog Industry." Canadian Journal of Agricultural Economics/Revue 36 (2): 313-35.

[5] Azzam, A., Nene, G., and Schoengold, K. 2015. "Hog
Industry Structure and the Stringency of Environmental Regulation.” Canadian Journal of Agricultural Economics/Revue 63 (3): 333-58.

[6] Moyer, J., Fitzpatrick, P., Diduck, A., and Froese, B. 2008. "Towards Community-Based Monitoring in Manitoba's Hog Industry.” Canadian Public Administration 51 (4): 637-58.

[7] Meulenberg, M. T. G., and Pennings, J. M. E. 2002. “A Marketing Approach to Commodity Futures Exchanges: A Case Study of the Dutch Hog Industry." Journal of Agricultural Economics 53 (1): 51-64.

[8] Qing, L., Fengjun, L., and Liming, C. 2012. "Study on Strategic Cooperation between Producing Area and Marketing Area about Healthy Breeding Industry of Live Pigs in China." Presented at the 22nd Annual World Symposium on "The Road to 2050: The China Factor", International Food and Agribusiness Management Association, Shanghai, China.

[9] Lu, F. J., Liu, Q., and Li, X. H. 2014. Strategic Analysis about the Development in Healthy Breeding Industry of Pigs. China: China Agriculture Press. 